\title{
SUSCETIBILIDADE ANTIMICROBIANA DE BACTÉRIAS OCORRENTES EM ÚLCERAS CRÔNICAS AOS EXTRATOS BRUTOS DE Prosopis juliflora
}

\section{Renata Soares da Silva}

Faculdade de Ciências Biológicas e da Saúde; Graduação em Enfermagem; Centro Universitário Cesmac, Brasil.

\section{Karla Maria Santos de Oliveira}

Faculdade de Ciências Biológicas e da Saúde; Graduação em Enfermagem; Centro Universitário Cesmac, Brasil.

\section{Giani Maria Cavalcante}

Doutoranda em Biotecnologia - Desenvolvimento e inovação tecnológica em Medicamentos Universidade Federal Rural de Pernambuco (UFRPE), Brasil.

E-mail: gianimc@icloud.com
RESUMO: Úlceras crônicas são suscetíveis à infecção devido à perda estéril da função de barreira inata da pele e dos anexos cutâneos, facilitando o desenvolvimento de comunidades microbianas. O objetivo do estudo foi investigar a suscetibilidade de bactérias associadas a úlceras crônicas aos extratos brutos de Prosopis juliflora. Os testes in vitro foram realizados com extratos brutos das folhas e casca do caule contra as estirpes de Escherichia coli (ATCC 25922), Pseudomonas aeruginosa (ATCC 27853), Staphylococcus aureus (ATCC 25923) e Proteus mirabilis (ATCC 7002), por meio de ensaio de difusão em ágar com poço e determinação da Concentração Inibitória Mínima (CIM). Os resultados mostraram que as estirpes de $E$. coli, $P$. aeruginosa, $S$. aureus e $P$. mirabilis foram mais suscetíveis aos extratos brutos da folha, com diâmetro de zona de inibição de 21,0;33,0;20,0;21,0 mm, respectivamente, enquanto $E$. coli e $S$. aureus foram mais suscetíveis aos extratos brutos da casca do caule, com diâmetro da zona de inibição de 21,5 e 20,0 mm, respectivamente. Os melhores valores de CIM foram registrados para os extratos brutos das folhas de P. juliflora. Estudo químico para a extração e o isolamento de compostos ativos é recomendado para realização de ensaios in vitro para investigar a atividade antimicrobiana destes compostos.

PALAVRAS-CHAVE: Atividade Antimicrobiana; Prosopis juliflora; Úlceras Crônicas.

\section{ANTIMICROBIAL SUSCEPTIBILIT Y OF BACTERIA IN CHRONIC ULCERS TO CRUDE EXTRACTS OF PROSOPIS JULIFLORA}

\begin{abstract}
Chronic ulcers are prone to infection due to the sterile loss of the innate barrier of the skin and cutaneous annexes, coupled to the development of microbial communities. Current study investigates the susceptibility of bacteria associated with chronic ulcers to crude extracts of Prosopis juliflora. In vitro tests with the crude extracts of leaves and stem bark were performed against strains of Escherichia coli (ATCC 25922), Pseudomonas aeruginosa (ATCC 27853), Staphylococcus aureus (ATCC 25923) and Proteus mirabilis (ATCC 7002), by a diffusion assay in agar and determination of Minimum Inhibiory Concentration (MIC). Results showed that E. coli, $P$. aeruginosa, $S$. aureus and $P$. mirabilis strains were affected by the crude extracts of the leaves, with a diameter of the inhibition zone measuring respectively 21.0; 33.0; $20.0 ; 21.0 \mathrm{~mm}$, whereas $E$. coli and $S$. aureus were more affected to the crude extracts of the stem bark, with an inhibition zone diameter of 21.5 and $20.0 \mathrm{~mm}$, respectively. Best MIC rates were reported for the crude extracts of $P$. juliflora leaves. Chemical studies for the extraction and isolation of compounds are recommended for the execution of $i n$ vitro assays to investigate the compounds' antimicrobial activity.
\end{abstract}


KEY WORDS: Prosopis juliflora; Chronic Ulcers; Antimicrobial Activity.

\section{INTRODUÇÃO}

As úlceras crônicas (UCs) se caracterizam por apresentar um processo de cicatrização tardio, com uma fase inflamatória muito longa, gerando um desequilíbrio nos fatores de crescimento do tecido, retardando a resposta dos fibroblastos, gerando matriz extracelular irregular e células fenotípicas alteradas (SILVA et al., 2014).

De acordo com Landis (2008) as principais úlceras crônicas são: úlceras por pressão, úlceras venosas e as úlceras diabéticas. Essas constituem um grande problema de saúde pública e sua etiologia provém de fatores como: doença arterial periférica, doença venosa crônica, traumas físicos, alterações nutricionais, entre outros (NOGUEIRA et al., 2015).

Uma das principais razões que compromete o processo de cicatrização das úlceras crônicas tornando a fase inflamatória longa, provavelmente é a causa persistente de colonização por bactérias (LANDIS, 2008). Segundo Folson et al. (2011) a infecção bacteriana de UCs é um problema comum e um dos principais motivos para o aumento do risco de morbidade e mortalidade de pacientes.

Várias espécies bacterianas são responsáveis pela infecção de úlceras crônicas, entretanto as espécies Escherichia coli, Pseudomonas aeruginosa, Enterococcus faecalis, Proteus mirabilis, Staphylococcus aureus e Staphylococcus saprophyticus são espécies comumente presentes nesses processos infecciosos (DAI et al., 2011). Sendo as espécies P. aeruginosa e P. mirabilis invasivas, podendo levar ao desenvolvimento de sepse, enquanto as demais contribuem ativamente para a condição crônica das úlceras (BURKATOVSKAYA et al., 2010).

Silva e colaboradores (2014) afirmam que, em virtude da infecção bacteriana recorrente, a antibioticoterapia é a forma mais usual de tratamento, e como consequência há o desenvolvimento de resistência bacteriana, agravando ainda mais a problemática das úlceras crônicas (DAI et al., 2011).
Neste contexto a busca por novos tratamentos antimicrobianos torna-se relevante e urgente, uma vez que a resistência aos antibióticos é um problema de saúde em todo o mundo, bem como é uma ameaça duradoura que provavelmente tardará a ser eliminada, em virtude da vantagem evolutiva dos microrganismos em cortar os riscos para a sua sobrevivência (FAUCI et al., 2014; LEE et al., 2013).

Dentre os novos tratamentos antimicrobianos destaca-se busca por substâncias naturais, uma vez que essas substâncias apresentam composição química que em geral minimiza o desenvolvimento de resistência por parte de microrganismos patogênicos (LEE et al., 2013), o que otimiza a busca de substâncias bioativas contra microrganismos associados a doenças de grande incidência.

O objetivo deste trabalho foi verificar a suscetibilidade de bactérias associadas a úlceras crônicas aos extratos brutos de Prosopis juliflora, em ensaio in vitro, como uma triagem inicial para trabalhos com substâncias isoladas da espécie e futuros ensaios toxicológicos e farmacológicos.

\section{METODOLOGIA}

A coleta de folhas e cascas de caule de $P$. juliflora foi realizada aleatoriamente em indivíduos arbóreos ocorrentes em área urbana na cidade de Maceió, Estado de Alagoas ( $9^{\circ} 39^{\prime} 59^{\prime \prime} \mathrm{S}$ e $35^{\circ} 44^{\prime}$ 6" W), durante o processo de poda urbana controlado e realizado pela Secretaria do Meio Ambiente do município. A espécie vegetal foi confirmada por profissionais do Herbário do Instituto de Meio Ambiente de Alagoas e uma exsicata foi depositada sob o registro de $n^{\circ}$ IMAL-9638.

Para obter os extratos, $5 \mathrm{~kg}$ de folhas e cascas de caule foram submetidos à secagem em estufa a $60{ }^{\circ} \mathrm{C}$ por 24 horas, triturados e extraídos, separadamente, com etanol $(5 \times 5 \mathrm{~L})$. Após a evaporação do solvente com o auxílio de rotaevaporador, sob pressão reduzida, foram obtidos $178 \mathrm{~g}$ do extrato bruto da folha (EBF) e $200 \mathrm{~g}$ de extrato bruto da casca do caule (EBC). Para os ensaios de suscetibilidade antimicrobiana os extratos EBF e EBC foram previamente solubilizados em dimetilsulfóxido 
0,01\% (DMSO), uma vez que este não interfere no crescimento bacteriano (OSTROSKY et al., 2008).

Os ensaios in vitro de suscetibilidade antimicrobiana foram realizados utilizando cepas de Escherichia coli (ATCC 25922), Pseudomonas aeruginosa (ATCC 27853), Staphylococcus aureus (ATCC 25923) e Proteus mirabilis (ATCC 7002) obtidos junto ao laboratório Labornew ${ }^{\circledR}$.

Para investigar a suscetibilidade antimicrobiana dos extratos brutos de $P$. juliflora, foram realizadas diluição em série dupla a partir da concentração máxima de $500 \mu \mathrm{g} / \mathrm{mL}$ até $7,8 \mu \mathrm{g} / \mathrm{mL}$. Os testes foram realizados através do ensaio de difusão em ágar por meio de poço, conforme a metodologia descrita por Nennaah (2013). Para esse ensaio cepas bacterianas foram cultivadas em meio Ágar Mueller-Hinton (AMH) a $37{ }^{\circ} \mathrm{C}$ por 24 horas. Após esse período as cepas foram suspensas, separadamente, em solução salina de $\mathrm{NaCl}$ a $0,85 \%$ e ajustada a uma turbidez de 0,5 da escala de MacFarland $\left(10^{8} \mathrm{CFU} / \mathrm{mL}\right)$, obtendo-se os inócuos bacterianos. Com auxílio de um swab estéril as cepas foram inoculadas, em placas de Petri com AMH; nessas placas foram feitas quatro cavidades de $6 \mathrm{~mm}$ de diâmetro com auxílio de pipetas de Pasteur estéreis. Em uma cavidade foram adicionados 20 $\mu \mathrm{L}$ de extrato bruto, em outra foram adicionados $20 \mu \mathrm{L}$ de DMSO 0,1\%, usado como controle negativo, e nas outras duas cavidades foram adicionados discos com $20 \mu \mathrm{L} / \mathrm{mg}$ de Ciprofloxacina e Gentamicina, usados como controles positivos. As placas foram mantidas em temperatura ambiente por 1 hora, para difusão dos tratamentos, e em seguida foram incubadas a $37^{\circ} \mathrm{C}$ por 24 horas. Após esse período, os halos de inibição formados em volta das cavidades foram mensurados. O experimento foi realizado separadamente para os extratos EBF e EBC e em triplicatas.

A determinação da Concentração Inibitória Mínima (CIM) foi realizada através do método de microdiluição, conforme as normativas estabelecidas pelo NCCLS (2003). As cepas foram normalizadas para uma concentração com base no padrão 0,5 da escala de McFarland (1,5 x $\left.10^{8} \mathrm{CFU} / \mathrm{mL}\right)$. Em ensaios independentes, utilizando placas de 96 poços contendo caldo Muller-Hinton (CMH), $5 \mu \mathrm{L}$ de inócuo bacteriano e $100 \mu \mathrm{L}$ de EBF e EBC de $P$. juliflora foram adicionados em cada poço, para um volume final de $200 \mu \mathrm{L}$. Como controle negativo foi utilizado DMSO $0,01 \%$ e como controles positivos os antibióticos Ciprofloxacina e Gentamicina. Em seguida as placas foram acondicionadas em incubadora bacteriológica a $37^{\circ} \mathrm{C}$, durante 24 horas. Após esse período, foram adicionados $30 \mu \mathrm{L}$ da solução resazurina $0,01 \%$. De acordo Zeni et al. (2008), o sistema de resazurina mede a atividade metabólica das células vivas através da redução a resorufina pela atividade celular no meio, e existe uma correlação direta entre a diminuição da resazurina no meio de crescimento e a atividade metabólica das células vivas. Duas horas após a aplicação de resazurina, as placas de 96 poços foram lidas por interpretação visual da cor em cada poço. A cor azul indicou a ausência de crescimento bacteriano e a cor rosa/ vermelho indicou o crescimento bacteriano (NENNAAH, 2013). Os experimentos foram realizados em triplicatas para concentrações de $500 \mu \mathrm{g} / \mathrm{mL}$ até $7,8 \mu \mathrm{g} / \mathrm{mL}$.

Os dados obtidos no ensaio de difusão em ágar por meio de poço (diâmetro de inibição) foram expressos como média \pm desvio padrão $(\mathrm{C} \pm \mathrm{DP})$ e as médias foram analisadas estatisticamente usando análise de variância (ANOVA), comparadas pelo teste de Tukey usando o software Bioestat versão 5.3. As diferenças foram consideradas significativas quando $p \geq 0,05$.

\section{RESULTADOS}

A suscetibilidade de espécies bacterianas ocorrentes em úlceras crônicas frente aos extratos de $P$. juliflora em diferentes concentrações está descrita na Tabela 1. Os resultados apontam a espécie E. coli como a mais suscetível aos extratos testados, apresentando médias de zona de inibição de halo de $21,5 \mathrm{~mm}$ para os EBF e EBC, em concentrações que variaram de 500 a 62,5 $\mu \mathrm{g} / \mathrm{mL}$, esses valores foram estatisticamente significativos quando comparados com o antibiótico padrão (controle positivo). 
Tabela 1. Suscetibilidade Antimicrobiana aos Extratos de Prosopis juliflora Usando Ensaios de Difusão em Ágar com Poço

\begin{tabular}{|c|c|c|c|c|}
\hline \multirow[t]{2}{*}{ Tratamentos } & \multicolumn{4}{|c|}{ Médias da Zona de Inibição $(\mathrm{mm} \pm \mathrm{DP})$} \\
\hline & E. coli & P. aeruginosa & S. aureus & P. mirabilis \\
\hline \multicolumn{5}{|l|}{ EBF } \\
\hline $500 \mu \mathrm{g} / \mathrm{mL}$ & $21,0 \pm 0,5^{\mathrm{b}}$ & $33,0 \pm 0,7^{a}$ & NA & $21,0 \pm 0,5^{b}$ \\
\hline $250 \mu \mathrm{g} / \mathrm{mL}$ & $20,0 \pm 0,7^{\mathrm{b}}$ & $32,5 \pm 1,0^{\mathrm{a}}$ & $\mathrm{NA}$ & $20,5 \pm 0,5^{b}$ \\
\hline $125 \mu \mathrm{g} / \mathrm{mL}$ & $20,5 \pm 0,5^{\mathrm{b}}$ & $32,5 \pm 0,5^{a}$ & $19,5 \pm 0,5^{b}$ & NA \\
\hline $62,5 \mu \mathrm{g} / \mathrm{mL}$ & $21,0 \pm 0,7^{\mathrm{b}}$ & NA & $20,0 \pm 0,7^{\mathrm{b}}$ & NA \\
\hline $31,2 \mu \mathrm{g} / \mathrm{mL}$ & $15,5 \pm 1,0^{c}$ & NA & NA & NA \\
\hline $15,6 \mu \mathrm{g} / \mathrm{mL}$ & $16,0 \pm 0,5^{c}$ & NA & $\mathrm{NA}$ & NA \\
\hline $7,8 \mu \mathrm{g} / \mathrm{mL}$ & NA & NA & NA & NA \\
\hline \multicolumn{5}{|l|}{ EBC } \\
\hline $500 \mu \mathrm{g} / \mathrm{mL}$ & $9,0 \pm 0,1$ & $16,6 \pm 1,0^{c}$ & $12,1 \pm 0,5^{c}$ & $9,5 \pm 0,7^{c}$ \\
\hline $250 \mu \mathrm{g} / \mathrm{mL}$ & $9,5 \pm 0,5$ & NA & $22,0 \pm 0,7^{\mathrm{a}}$ & NA \\
\hline $125 \mu \mathrm{g} / \mathrm{mL}$ & $21,5 \pm 0,5^{\mathrm{b}}$ & NA & $13,0 \pm 1,0^{c}$ & NA \\
\hline $62,5 \mu \mathrm{g} / \mathrm{mL}$ & $16,5 \pm 0,7^{c}$ & NA & $12,5 \pm 0,5^{c}$ & NA \\
\hline $31,2 \mu \mathrm{g} / \mathrm{mL}$ & $6,5 \pm 1,0^{\mathrm{d}}$ & NA & NA & NA \\
\hline $15,6 \mu \mathrm{g} / \mathrm{mL}$ & NA & NA & NA & NA \\
\hline $7,8 \mu \mathrm{g} / \mathrm{mL}$ & $\mathrm{NA}$ & $\mathrm{NA}$ & NA & NA \\
\hline DMSO $0,1 \%$ & NA & NA & NA & NA \\
\hline Ciprofloxacina & $28,5 \pm 0,5^{a}$ & $34.0 \pm 0,25^{a}$ & $32,5 \pm 0,50^{\mathrm{a}}$ & $34,0 \pm 0,5^{a}$ \\
\hline Gentamicina & $22,0 \pm 0,5^{\mathrm{b}}$ & $19,5 \pm 0,25^{b}$ & $21,5 \pm 0,25^{\mathrm{b}}$ & $20,0 \pm 0,5^{b}$ \\
\hline
\end{tabular}

$\mathrm{NA}=$ não ativo.

Na mesma coluna, médias seguidas de letras iguais não diferem estatisticamente em si $(p \leq 0,05)$.

Os valores de CIM variaram entre 7,8 e $500 \mu \mathrm{g} /$ $\mathrm{mL}$, sendo os menores valores registrados para $\mathrm{EBF}$ (Tabela 2).

Tabela 2. Concentração Inibitória Mínima (CIM) dos Extratos de Prosopis juliflora frente a Bactérias Associadas a úlceras Crônicas usando o Método de Microdiluição em Placas de 96 Poços

\begin{tabular}{ccc} 
& & (continua) \\
\hline Cepa bacteriana & Tratamento & MIC $(\mu \mathrm{g} / \mathbf{m L})$ \\
\hline \multirow{3}{*}{ E. coli } & EBF & 62,5 \\
& EBC & 125 \\
& Ciprofilaxina & 7,8 \\
& Gentamicina & 7,8 \\
& DMSO & NA \\
\hline
\end{tabular}

\begin{tabular}{ccc} 
& & (conclusão) \\
\hline \multirow{4}{*}{ P. aeruginosa } & EBF & 125 \\
& EBC & 500 \\
& Ciprofilaxina & 7,8 \\
& Gentamicina & 15,6 \\
& DMSO & NA \\
\hline \multirow{4}{*}{ S. aureus } & EBF & 62,5 \\
& EBC & 250 \\
& Ciprofilaxina & 7,8 \\
& Gentamicina & 7,8 \\
P. mirabilis & DMSO & NA \\
& EBF & 250 \\
& EBC & NA \\
& Ciprofilaxina & 7,8 \\
& Gentamicina & 15,6 \\
& DMSO & NA
\end{tabular}




\section{DISCUSSÃO}

Em geral as úlceras crônicas exibem um período inflamatório altamente persistente, que se caracteriza pelo influxo de leucócitos polimorfonucleares para o local da úlcera e um desequilíbrio de várias citocinas (BJARNSHOLT et al., 2008). De acordo com Percival et al. (2012) esse desequilíbrio deve-se, em parte, a presença contínua de bactérias nas úlceras o que ocasiona infiltração adicional de leucócitos polimorfonucleares e alta produção de metaloproteinases de matriz, retardando o processo cicatricial e potencializando a condição crônica da úlcera.

Segundo Prince et al. (2009) rotineiramente o uso de antibiótico é o mais empregado para o tratamento de úlceras crônicas, entretanto, seu uso e benefício ainda é pouco evidente na cicatrização de feridas, uma vez que a resistência bacteriana a esses antibióticos aparecem como o principal problema da antibioticoterapia, contribuindo pouco para redução da carga bacteriana. Folson et al. (2011), testando os antibióticos rifampicina, vancomicina, ampicilina e ciprofloxacina frente a isolados de úlceras crônicas, detectaram que nenhum antibiótico foi capaz de apresentar resultados consistentes em relação à inibição do crescimento desses isolados, sugerindo desenvolvimento de resistência dos isolados frente a esses antibióticos.

Neste contexto a busca por métodos alternativos para tratamento da infecção bacteriana de úlceras crônicas, atualmente, é emergente e, sobretudo urgente, uma vez que as úlceras crônicas causam substancial morbidade e ônus econômico que é suportado de forma desproporcional por seus portadores (SIENKIEWICZ et al., 2014).

Os resultados obtidos nesse trabalho apontam que as espécies bacterianas $E$. coli, P. aeruginosa, S. aureus e P. mirabilis, comumente presentes em úlceras crônicas, são suscetíveis ao extrato bruto das folhas (EBF) de $P$. juliflora, apresentando halos de inibição de 21,$0 ; 33,0 ; 20,0 ; 21,0 \mathrm{~mm}$, respectivamente, valores esses que quando comparados ao antibiótico padrão são estatisticamente significativos, não diferindo entre si para $p \leq 0,05$. Enquanto as espécies $E$. coli e $S$. aureus foram suscetíveis ao extrato bruto do caule (EBC), com halos de inibição de 21,5 e 20,0 mm, respectivamente.
Sukirtha e Growther (2012) testando extrato metanólico de folhas de $P$. juliflora detectaram suscetibilidade de $S$. aureus a esses extratos com formação de halo de inibição de $20,0 \mathrm{~mm}$. Entretanto, esses mesmos autores detectaram resistência a esses extratos pelas cepas $E$. coli e P. aeruginosa com halos de inibição de $12 \mathrm{~mm}$ e $4 \mathrm{~mm}$, respetivamente. Quando os resultados deste trabalho são comparados com os dos referidos autores, verifica-se que é possível corroborar a suscetibilidade de $S$. aureus frente aos extratos de $P$. juliflora, o que potencializa a espécie para investigação minuciosa acerca de sua atividade antimicrobiana frente a compostos isolados dessa espécie. Destarte, é possível refutar a resistência das espécies $E$. coli e P. aeruginosa frente aos extratos de P. juliflora, estimulando também a investigação de suscetibilidade antimicrobiana dos compostos isolados dessas espécie vegetal frente a essas cepas bacterianas, em ensaios in vitro.

Napare colaboradores (2012) também registraram suscetibilidade de extratos das folhas de P. juliflora por E. coli e S. aureus, com halos de inibição de 20,0 e 18,0 $\mathrm{mm}$ respectivamente. Entretanto, não foi determinada a Concentração Inibitória Mínima (CIM), que de acordo com Ostrosky et al. (2008), esta é uma etapa da investigação de suscetibilidade antimicrobiana necessária uma vez que determina a menor quantidade de substância que inibe o crescimento de microrganismos, sendo possível avaliar aspectos toxicológicos e microbiológicos pertinentes aos extratos oriundos de vegetais. Neste trabalho os menores valores de CIM foram registrados para o extrato bruto das folhas (EBF) de P. juliflora.

Os resultados de suscetibilidade apresentados pelas espécies bacterianas $E$. coli, P. aeruginosa, $S$. aureus e P. mirabilis, ocorridos em úlceras crônicas, frente aos extratos brutos de folhas e caules de P. juliflora, sugerem uma potencial atividade antimicrobiana dos compostos presentes nos extratos, fomentando a continuidade dessa investigação usando compostos isolados, além da investigação dos extratos de outras partes vegetais da espécie P. juliflora.

\section{CONCLUSÃO}

As espécies Escherichia coli, Pseudomonas aeruginosa, Enterococcus faecalis, Proteus mirabilis, Staphylococcus aureus e Staphylococcus saprophyticus, 
registradas como predominantes em úlceras crônicas, apresentaram suscetibilidade significativa frente aos extratos brutos de folhas e caules oriundos da espécie vegetal Prosopis juliflora, potencializando investigações futuras com compostos isolados dessa espécie.

\section{REFERÊNCIAS}

BJARNSHOLT, T.; KIRKETERP-MOLLER, K.; JENSEN, P. O.; MADSEN, K. G.; PHIPPS, R.; KROGFELT, K.; HOIBY, N.; GIVSKOV, M. Why chronic wounds will not heal: a novel hypothesis. Wound Repair Regeneration, v. 16, n. 1, p. 2-10, 2008.

BURKATOVSKAYA, M.; TEGOS, G.; DEMIDOVA, T.; CASTANO, A. P.; SWIETLIK, E.; HAMBLIN, M. R. Use of chitosan bandage to prevent fatal infections developing from highly contaminated wounds in mice. Biomaterials, v. 27 , n. 22 , p. $4157-4164,2006$.

DAI, T.; TNAKA, M.; HUANG, Y.; HAMALIN, M. R. Chitosan preparations for wounds an burns: antimicrobial and wound-healing effects. Expert Rev Anti Infect Ther., v. 9, n. 7, p. 857-879, 2011.

FAUCI, A.; MARSTON, H. The perpetual challenge of antimicrobial resistance. JAMA, v. 311, n. 18, p. 18531854, 2014.

FOLSOM, J. P.; BAKER, B.; STEWART, P. S. In vitro efficacy of bismuth thiols against biofilms formed by bacteria isolated from human chronic wounds. J Appl Microbiol., v. 111, n. 2, p. 989-996, 2011.

LANDIS, S. Chronic Wound Infection and Antimicrobial Use. Adv Skin Wound Care, v. 21, n. 2, p. 31-40, 2008.

LEE, C.; CHO, H.; JEONG, B.; LEE, S. Strategies to minimize antibiotic resistance. Int J Environ Res Public Health, v. 10, n. 9, p. 4274-4305, 2013.

NAPAR, A.; BUX, H.; ZIA, M.; AHMAD, M.; IQBALD, A.; ROOMI, S, MUHAMMAD, I.; SHAH, S. Antimicrobial and antioxidant activities of Mimosaceae plants; Acacia modesta Wall (Phulai), Prosopis ceneraria (Linn) and Prosopis juliflora (Swartz). J Medicinal Plants Res., v. 6, n. 15, p. $7723-7728,2012$.
NENAAH, G. Antimicrobial activity of Calotropis procera Ait (Asclepiadaceae) and isolation of four flavonoid glycosides as the active constituents. World J Microbiol Biotechnol., v. 29, n. 1, p. 1255-1262, 2013.

NCCLS. Clinical and Laboratory Standards institute. Performace standards for antimicrobial disk susceptibility tests: approved standard. Wayne, Pennsylvania, 2003. ISBN 1-56238-485-6.

NOGUEIRA, G. A.; CAMAC, A. C. L.; OLIVEIRA, B. G. R. B.; SANTOS, L. S. F. Caracterização dos protocolos referentes a feridas: revisão integrativa. J Nursing UFPE on line, v. 9, n. 3, p. 7723-7728, 2015.

OSTROSKY, E. A.; MIZUMOTO, M. K.; LIMA, M. E. L.; KANEKO, T. M.; NISHIKAWA, S. O.; FREITAS, B. R. Métodos para avaliação da atividade antimicrobiana e determinação da concentração inibitória mínima (CIM) de plantas medicinais. Brazilian J Pharmacognosy, v. 18, n. 2, p. 301-307, 2008.

PERCIVAL, S.; HILL, K.; WILLIAMS, D.; HOOPER, S.; THOMAS, D.; COSTERTON, J. A review of the scientific evidence for biofilms in wounds. Wound Repair Regeneration, v. 20, n. 2, p. 647-657, 2012.

PRINCE, L.; LIU, C.; MELENDEZ, J.; FRANKEL, Y.; ENGELTHALER, D.; AZIZ, M.; BOWERS, J.; RATTYAU, R.; RAVEL, J.; KINGSLEY, C.; KEIM, P.; LAZARUS, G.; ZENILMAN, J. Community analysis of chronic wound bacteria using 16s rRNA gene-bases pyrosequencing: impact of diabetes and antibiotics on chronic wound microbiota. PlosOne, v. 4, n. 7, p. 64-72, 2009.

SIENKIEWICZ, M.; POZNAN, K.; KASZUBA, A.; KOWALCZYK, E. The antibacterial activity of geranium oil against gram-negative bacteria isolated from difficult-toheal wound. Burns, v. 40, n. 2, p. 1046-1051, 2014.

SILVA, P. N.; ALMEIDA, O. A. E.; ROCHA, I. C. Terapia tópica no tratamento de feridas. Enfermería global, v. 2 , n. 3, p. 46-58, 2014.

SUKIRTHA, K.; GROWTHER, L. Antibacterial, antifungal and phytochemical analysis of sected medicinal plants. $\mathbf{J}$ Nat Prod Plant Resour., v. 2, n. 6, p. 644-648, 2012. 
ZENI, O.; PALUMBO, R.; BERNINI, R.; ZENI, L.; SARTI, M.; SCARFI, M. R. Cytotoxicity investigation on cultured human blood cells treated with single-wall carbono nanotubes. Sensors, v. 8, n. 1, p. 488-499, 2008.

Recebido em: 25 de setembro de 2015 Aceito em: 08 de novembro de 2015 